\title{
Effect of Goal-directed Haemodynamic Therapy Guided by Non-invasive Monitoring on Perioperative Complications in Elderly Hip Fracture Patients Within an Enhanced Recovery Pathway.
}

Juan Victor Lorente ( $\boldsymbol{}_{\text {juanvictor.lorente@gmail.com })}$

Hospital Juan Ramón Jiménez https://orcid.org/0000-0002-3158-7014

Francesca Reguant

Fundació Althaia de Manresa: Fundacio Althaia de Manresa

Anna Arnau

Fundació Althaia de Manresa: Fundacio Althaia de Manresa

Marcelo Borderas

Fundació Althaia de Manresa: Fundacio Althaia de Manresa

Juan Carlos Prieto

Fundació Althaia de Manresa: Fundacio Althaia de Manresa

Jordi Torrallardona

Fundació Althaia de Manresa: Fundacio Althaia de Manresa

Laura Carrasco

Fundació Althaia de Manresa: Fundacio Althaia de Manresa

\section{Patricia Solano}

Fundació Althaia de Manresa: Fundacio Althaia de Manresa

Isabel Pérez

Fundació Althaia de Manresa: Fundacio Althaia de Manresa

Carla Farré

Fundació Althaia de Manresa: Fundacio Althaia de Manresa

Ignacio Jiménez

Hospital Universitario Virgen del Rocio Unidad de Anestesiologia y Reanimacion y Areas Quirurgicas

HM-HI-HRT

Javier Ripollés-Melchor

Hospital Infanta Leonor

Manuel Ignacio Monge

Hospital of Jerez de la Frontera: Hospital de Jerez de la Frontera

Joan Bosch

Universitat Internacional de Catalunya 
Research

Keywords: enhanced recovery after surgery, enhanced recovery pathway, fluid therapy, goal-directed haemodynamic therapy, hip fracture, intraoperative complications, mortality, postoperative complications

Posted Date: July 24th, 2021

DOI: https://doi.org/10.21203/rs.3.rs-736990/v1

License: (c) (i) This work is licensed under a Creative Commons Attribution 4.0 International License.

Read Full License 


\section{Abstract}

Background: Goal-Directed Hemodynamic Therapy (GDHT) has been shown to reduce morbidity and mortality in high-risk surgical patients. However, there is little evidence of its efficacy in patients undergoing hip fracture surgery. This study aims to evaluate the effect of GDHT guided by non-invasive haemodynamic monitoring on perioperative complications in patients undergoing hip fracture surgery.

Methods: Patients $>64$ years undergoing hip fracture surgery within an Enhanced Recovery Pathway were enrolled in this single-center, non-randomized, intervention study with a historical control group and 12-months follow-up. Exclusion criteria were patients with pathological fractures, traffic-related fractures and refractures. Control group patients received the standard care given at our hospital. Intervention group patients received an individualized management strategy aimed at achieving an optimal stroke volume by fluid administration, in addition to a systolic blood pressure $>90 \mathrm{mmHg}$ and an optimal cardiac index according to the patient's age and baseline metabolic equivalents. No changes were made between groups in the enhanced recovery protocols, nor in the composition of the multidisciplinary team during the study period. Primary combined outcome was perioperative complications. Intraoperatively: haemodynamic instability, sustained cardiac arrhythmias. Postoperative complications: cardiovascular, respiratory, infectious and renal complications. Secondary outcomes were administered fluids, vasopressor requirements, perioperative transfusion, length of hospital stay, readmission and one-year survival.

Results: 551 patients (Control group=272; Intervention group=279). Intraoperative haemodynamic instability was lower in the intervention group (37.5\% vs $28.0 \%$; $p=0.017)$. GDHT patients had fewer postoperative cardiovascular (18.8\% vs $7.2 \%$; $<$ < 0.001$)$, respiratory $(15.1 \%$ vs $3.6 \% ; p<0.001)$ and infectious complications ( $21 \%$ vs $3.9 \%$; $p<0.001$ ) but not renal $(12.1 \%$ vs $33.7 \% ; p<0.001)$. Intervention group patients had less vasopressors requirements $(p<0.001)$ and received less fluids $(p=0.001)$ than control group. Fewer patients required transfusion in GDHT group $(p<0.001)$. For intervention group patients, median length of hospital stay was shorter $(p<0.001)$ and one-year survival higher $(p<0.003)$.

Conclusions: The use of GDHT decreases intraoperative complications and postoperative cardiovascular, respiratory and infectious but not postoperative renal complications. This strategy was associated with a shorter hospital stay and increased one-year survival.

Trial registration: Clinicaltrials.gov: NCT02479321

\section{1- Background}

Hip fracture represents an increasingly serious public health problem with a significant impact on life expectancy and economic burden (Veronese and Maggi 2018). Patients with hip fractures are at high risk of perioperative complications (Reguant et al. 2019) due to a limited cardiorespiratory reserve when facing the fracture and surgery-associated stress (Cowan et al. 2017). Moreover, postoperative 
complications related to hip fracture are a known independent risk factor for mortality (Griffiths et al. 2021).

Enhanced recovery pathways (ERP) comprise perioperative evidence-based care interventions designed to improve outcomes after surgery (Ljungqvist et al. 2017). Perioperative hemodynamic optimization is a key element of the ERP (Miller et al. 2015). The Goal-Directed Hemodynamic Therapy (GDHT) has been shown to reduce morbidity and mortality in high-risk surgical patients (Giglio et al. 2016). Nevertheless, in daily clinical practice, patients with hip fracture are usually intraoperatively monitored with routine haemodynamic parameters such as blood pressure and heart rate (Reguant et al. 2019). However, these standard physiological variables result insufficient for assessing an adequate balance between oxygen delivery $\left(\mathrm{DO}_{2}\right)$ and consumption $\left(\mathrm{VO}_{2}\right)$ (Lugo G, Arizpe $\mathrm{D}$, Dominguez $\mathrm{G} 1993$ ). This $\mathrm{DO}_{2} / \mathrm{VO}_{2}$ imbalance may eventually lead to intraoperative tissue hypoperfusion, facilitating the appearance of postoperative complications (Merry and Mitchell 2018).

Currently, there are monitoring platforms that provide advanced haemodynamic parameters to guide GDHT in a non-invasive way to avoid the complications of invasive techniques (Teboul et al. 2016).

The present study aimed to evaluate the effect of GDHT guided by non-invasive haemodynamic monitoring on perioperative complications in patients undergoing surgical hip fracture repair within an Enhanced Recovery Pathway (ERP).

\section{2- Methods}

This manuscript was written according to CONSORT statement. The study was approved by an independent Ethics Committee (Fundació Unio Catalana Hospitals) on 27 January 2015 (CEIC 15/03). All patients signed an informed consent to participate. The study was conducted according to the Declaration of Helsinki and all local legal and regulatory requirements. Trial registration: NCT02479321 $(24 / 06 / 2015)$

\subsection{Study design}

Single-centre, non-randomised, hospital-based intervention study with a historical control group (CG) and 12-month follow-up after hospital discharge.

\subsection{Inclusion / Exclusion criteria}

Patients over 64 years with hip fracture within an Enhanced Recovery Pathway (ERP) who underwent surgical treatment were included.

Exclusion criteria were: patients with pathological fractures, traffic-related fractures, refractures, patients with known contraindication or limitations to advanced hemodynamic monitoring with ClearSight ${ }^{\circledR}$ system and EV1000 platform (Edwards Lifesciences, Irvine, USA) (Saugel et al. 2015): patients with Raynaud disease, with aortic valve prosthesis, proximal aortic aneurysm, known intra-cardiac shunts; 
moderate to severe mitral or aortic regurgitation; moderate to severe aortic or mitral stenosis, patients with poor quality arterial waveform signal (see below), patients with significant preoperative psychomotor agitation.

\subsection{Conduct of the study}

2.3.1. Perioperative management common to both groups.

Both groups were treated during the perioperative period in a multidisciplinary Enhanced Recovery Pathway (ERP) unit created in 2010 exclusively dedicated to patients undergoing hip fracture repair (Reguant et al. 2019). (A detailed description of this unit is in Additional file 1).

\section{Intraoperative period}

All subjects received standard of care with a 3-lead electrocardiogram, pulse oximetry, and two peripheral intravenous lines. Patients in both groups received standard measures to maintain oxygen saturation by pulse oximetry $>94 \%$ and heart rate $(\mathrm{HR})<100$ beats/min. Anaesthetic technique was at the discretion of the anesthetist.

\section{Post-Anaesthetic Care Unit (PACU)}

After surgery, patients were treated in the PACU. The attendant physician determined discharge from this unit according to the local protocol.

\subsubsection{Study arms}

\section{Control group}

Data from patients who underwent surgery for hip fracture between October 2010 and November 2011 with follow-up to December 2012 were used for the CG (Reguant et al. 2019).

Haemodynamic management was at the discretion of the attending anesthetist, using fluid therapy with crystalloids (normal saline, lactated Ringer or IsofundinÒ), colloids (VoluvenÒ, Gelaspan Ò), and/or cardiovascular drugs (in bolus - ephedrine - or continuous infusion - noradrenaline, dobutamine).

Non-invasive, intermittent arterial pressure measurement was obtained at least every 5 minutes using a cuff (Dahtex Ohmeda-GE S/5 Aespire Ò).

\section{Intervention group}

Data from patients who underwent surgery for hip fracture between June 2015 and February 2018 with follow-up to March 2019 were used as the IG.

Pre- and intraoperative non-invasive hemodynamic monitoring was conducted using ClearSight ${ }^{\circledR}$ monitor (Edwards Lifesciences, Irvine, USA). This monitoring system is based on the volume clamp method to 
continuously measure arterial pressure and the Physiocal method that periodically recalibrates the system (Saugel et al. 2015). Baseline haemodynamic measurements were taken when the Physiocal value exceeded 30 (Wesseling, K H; de Wit, B; Van der Hoeven, A;Van Goudoever 1995). If a Physiocal value over 30 was not obtained after 7 minutes' monitoring, the patient was excluded due to a poor quality arterial waveform signal (Wesseling, $\mathrm{K} \mathrm{H}$; de Wit, B; Van der Hoeven, A;Van Goudoever 1995).

Haemodynamic optimisation was performed according to the following GDHT protocol.

\section{GDHT protocol (Figure 2):}

Three groups of cardiac index $(\mathrm{Cl})$ goals were formed according to age and prior functional capacity (METS) (Montenij et al. 2014). Additional file 2.

Fluids were given based on a protocolized haemodynamic algorithm to achieve and maintain an adequate Indexed Stroke Volume (SVI) using crystalloids ( $0.9 \%$ Saline, Lactated Ringer or Isofundin Ò) or colloids (if preoperative glomerular filtration rate was above $60 \mathrm{~mL} / \mathrm{min}$ using MDRD equation (Ishihara 2014)- Voluven Ò, Gelaspan Ò). Choice of fluid type was based on anaesthesiologist criteria.

Vasopressor was administered to maintain systolic arterial pressure above $90 \mathrm{mmHg}$ (in bolus ephedrine, phenylephrine - or continuous infusion - noradrenaline). Continuous infusion of dobutamine was added to achieve individualized cardiac index goal.

\section{Phase 1: Preoperative resuscitation}

On arrival in the surgical area, patients received a fluid bolus (FB) of $250 \mathrm{ml}$ for 5 minutes. If SVI increased by $10 \%$ or more (FirstFluid Bolus Responder), the fluid bolus was repeated (Cecconi et al. 2011). Fluid boluses of $250 \mathrm{ml}$ were repeated until the SV failed to increase by $10 \%$.

Once preoperative resuscitation was completed, prophylactic antibiotic was infused (Additional file 1). This fluid contribution covered the estimated insensible losses during surgery (Jacob et al. 2007).

\section{Phase 2: Post-induction optimisation}

Post-induction optimisation began 15 minutes after the surgical incision, if the haemodynamic stabilisation was achieved (SAP and heart rate variation $<10 \%$ for 3 minutes); meanwhile, the haemodynamic priority was the maintenance of arterial pressure above goal set (Tassoudis et al. 2011).

Haemodynamic optimisation consisted of a $100 \mathrm{ml}$ fluid bolus administered for less than 3 minutes (Guinot et al. 2015; Mallat et al. 2015; Marik 2015; Muller et al. 2011). If SVI rose >10\%, the $100 \mathrm{ml}$ fluid bolus was repeated. The trigger SVI during surgery was calculated by subtracting $10 \%$ from the SVI obtained from the last positive $100 \mathrm{ml}$ fluid bolus (Muñoz et al. 2016). 
If any of SAP over $90 \mathrm{mmHg}$ and SVI superior to trigger SVI were not achieved, SVI was analysed. If it was lower than the trigger SVI, a $100 \mathrm{ml}$ fluid bolus was administered.

If SVI was higher than trigger SVI, Cl determined our decision. If its value was under goal level, dobutamine was added. When $\mathrm{Cl}$ was above goal level, a vasopressor was chosen.

After each therapy, we re-evaluated the achievement of SAP and SVI goals.

\subsection{Measurements and data handling}

\subsubsection{Procedure}

Intraoperative haemodynamic parameters (arterial pressure, heart rate, $\mathrm{SpO}_{2}$ in $\mathrm{CG}$ and also $\mathrm{Cl}$ and $\mathrm{SVI}$ in IG) were registered at 15-minute intervals. Haemodynamic instability, between intervals was registered as an event in the next record. Fluids and cardiovascular drugs used from the patient's arrival in the surgical area to their admission to the PACU were collected. In both groups, the evaluation of intraoperative complications, was based on the intraoperative anesthesia charts, whereas the postoperative complications were documented in the clinical course and hospital discharge report.

Post-discharge follow-up consisted of a structured telephone interview at 1, 3, 6 and 12 months after surgery. When the information could not directly be obtained from the patients (including deceased patients), the interview was done with next of kin or carer.

\subsubsection{Assessment of outcomes.}

\section{Primary outcome measures}

The primary combined outcome was the percentage of patients who developed perioperative complications:

- Intraoperatively: haemodynamic instability, defined as one measurement of SAP $<90 \mathrm{mmHg}$ in the CG and for at least one minute in the IG, or the presence of sustained cardiac arrhythmias.

- Postoperatively: postoperative complications as explained in Supplementary Appendix C

\section{Secondary outcome measures}

Total intraoperative volume and type of administered fluids, doses of cardiovascular drugs used, perioperative packed red blood cell transfusion, length of hospital stay, readmission within 30 days of surgery, and survival within 12 months after surgery.

\subsection{Statistical analysis}

2.5.1. Sample size 
The rate of intraoperative haemodynamic instability described with standard of care was $37.5 \%$ (Reguant et al. 2019). We planned a relative risk reduction of $30 \%$ in IG.

To achieve a power of $80 \%$ using a bilateral $\chi^{2}$-square test for two independent samples with a level of significance of $0.05,538$ patients had to be included ( 269 patients in each group). With a potential dropout of $5 \%, 568$ patients were included.

The percentage of patients who developed one or more postoperative complications in CG was $45.2 \%$. A meta-analysis by Grocott and colleagues suggested a RR reduction of 0.68 for complications in patients undergoing major surgery (Grocott et al. 2013). A sample size of 568 patients, 284 in each group, would have $80 \%$ power to detect a reduction of at least $22 \%$ in the number of IG patients presenting one or more postoperative complications, using a bilateral $\chi^{2}$-square test for two independent samples.

\subsubsection{Statistical analysis}

Categorical variables were presented as absolute values and relative frequencies. Continuous variables are summarised as means and standard deviation for normal distribution and by the median and interquartile range (IQR) $\left(25^{\text {th }}\right.$ to $75^{\text {th }}$ percentiles) for non-normal distributions.

In the bivariate analysis, we used the Student's t-test or the non-parametric Mann-Whitney U test for continuous variables. We used the $\chi^{2}$-square test for categorical variables, and Fisher's exact test or bilateral exact $p$-values in contingency tables when the expected frequencies were less than five.

One-year survival Kaplan-Meier curves were constructed, and the log-rank test was used to compare them. Crude and adjusted hazard ratios (HR) and confidence intervals ( $\mathrm{Cl}$ 95\%) were calculated using Cox proportional regression models. The proportionality of hazards was verified by examining Schoenfeld residual plots.

Outcomes were analysed on an intention-to-treat basis. The level of statistical significance was two-sided $5 \%(p<0.05)$. The IBM SPSS Statistics v.26 (IBM Corporation ${ }^{\circledR}$, Armonk, New York) and Stata v.14 (StataCorp LP®, College Station, Texas) programs were used for statistical analysis.

\section{3- Results}

A total of 551 patients were recruited. Study flowchart is shown in figure 1. Table 1 shows the baseline characteristics of the 272 patients in CG and the 279 patients in IG.

\subsection{Primary Outcome}

Intraoperative and postoperative complications are shown in table 2. The number of patients with intraoperative haemodynamic instability was lower in IG (37.5\% vs $28.0 \% ; p=0.017)$. The median number of episodes of intraoperative haemodynamic instability in IG was lower than in the CG [2 (IQR 1 to 4) vs 1 (IQR 1 to 2 ), $p<0.001]$. 
Postoperative complications rates were $42.3 \%$ in the IG versus $45.2 \%$ in CG $(p=0.489)$. Patient in the IG had fewer cardiovascular complications (18.8\% vs 7.2\%; $p<0.001$ ), fewer respiratory complications (15.1\% vs 3.6\%; $p<0.001)$ and postoperative infections (21\% vs 3.9\%; $p<0.001)$. However, IG patients had more renal complications (12.1\% vs 33.7\%; $p<0.001)$. No differences in postoperative renal complications were observed between groups in patients with normal creatinine value at hospital admission. (Additional file 6)

\subsection{Secondary Outcomes}

\subsubsection{Fluid volumes, vasopressor doses and perioperative transfusion}

Details of fluid volumes and vasopressor doses in both groups are shown in table 3.

$29.4 \%$ of IG patients were responders to the first fluid bolus performed. Patients in the IG received less fluid [2.600 ml (IQR 1700 to 2700) vs $850 \mathrm{ml}$ (IQR 750 to 1050); p=0.001] and vasopressors (39.7\% vs 25.5\%; $p<0.001$ ) than CG. Lactated Ringer's was the fluid most used during the intraoperative period in CG patients $(73.9 \%$ vs $4.3 \%$; $p<0.001)$ while saline was chosen more often in the intraoperative period in IG (25\% vs $95.7 \% ; p=0.001)$. Fewer patients in IG received colloids than in CG (59.2\% vs $9 \%$; $p<0.001)$.

Fewer patients required packed red blood cells (PRBC) transfusion in IG (73.5\% vs 44.4\%; $p<0.001)$, with a lower median number of PRBC among transfused patients in IG [2 (IQR 2 to 4) vs 2 (IQR 1 to 2); p<0.001].

\subsubsection{Length of stay and survival within 12 months of surgery}

The median length of stay was shorter for patients in the IG (median days: 11 vs 8; p < 0.001) (Table 2).

Demographic and clinical variables associated with one-year mortality in the bivariate analysis appear in Additional file 4. Figure 3 shows the Kaplan-Meier survival curves for both groups. The likelihood of oneyear survival was higher in IG (log-rank test=9.17; $p=0.003$ ) (see Figure 3), with a crude HR of 0.56 (95\% Cl: 0.39 to 0.82). Multivariate analysis (Additional file 5) showed that independent prognostic factors for one-year survival were: age (HR: 1.09; 95\% Cl: 1.05 to 1.12), male gender (HR: 2.10; 95\% Cl: 1.43 to 3.11 ), low (HR: 2.33; 95\% Cl: 1.29 to 4.23) and high comorbidity (HR: 2.84; 95\% Cl: 1.67 to 4.83), according to the Charlson Index, postoperative cardiovascular complications (HR: 3.85; 95\% Cl: 2.49 to 5.96), need for reintervention (HR: $5.31 ; 95 \% \mathrm{Cl}: 1.58$ to 17.86 ) and belonging to the intervention group*. The adjusted HR for the IG was 0.61 (95\% Cl: 0.39 to 0.95$)$.

\section{4- Discussion}

The use of GDHT guided by non-invasive haemodynamic monitoring in patients undergoing hip fracture surgery within an ERP, was associated with a reduction in intraoperative complications (haemodynamic instability, arrhythmias) and postoperative cardiovascular, respiratory and infectious complications, but not postoperative renal complications. This strategy was also associated with a shorter hospital stay and increased survival one year after surgery. 
Preoperative chronic conditions and insufficient preoperative optimization in this patient profile, associated with intraoperative conditions such as intraoperative bleeding and hypovolemia, predispose these elderly patients to hemodynamic instability or arrhythmias during surgery (Alecu et al. 2010); (Rocos et al. 2017). The occurrence of intraoperative complications may compromise the balance between tissue oxygen delivery and oxygen consumption, and increase the patient's susceptibility to postoperative complications (Merry and Mitchell 2018); (Beecham et al. 2020).

Our results showed a significant decrease in intraoperative haemodynamic instability episodes in patients in the IG, similarly to a recently published study (Davies et al. 2019). In addition, patients in the IG had fewer postoperative cardiovascular, respiratory and infectious complications. These results may be due to improvements in haemodynamic control of these patients as a result of GDHT guided by a noninvasive monitoring system implemented. One of its main objectives is to avoid intraoperative hypoperfusion (Brienza et al. 2019) which may have been reflected in fewer postoperative complications in IG.

A higher incidence of postoperative AKI found in IG may be due to several reasons. First, patients in the IG have more risk factors for postoperative AKI according to published articles (Meersch et al. 2017). Secondly, patients treated with GDHT received higher amounts of $0.9 \%$ saline. Hyperchloremic acidosis associated with saline infusion is detrimental to renal artery blood flow velocity and renal cortical tissue perfusion (Chowdhury et al. 2012). Third, the AKI definition itself. A single and transient, postoperative serum creatinine elevation above a very sensitive level, was considered a renal complication. An isolated elevation could neither be associated with kidney cell damage (Hahn 2015) nor be significant compared to baseline value. In patients with normal creatinine value at hospital admission, no differences in the risk of suffering postoperative renal complications were observed between the groups. The limitations of AKI definition and the influence on mortality only by postoperative creatinine elevations associated with kidney cell damage, may explain a significant decrease in mortality one year after surgery, despite an increase in postoperative renal complications in IG.

The GDHT protocol applied in this study differs from that used in the most recent trials in this patient profile (Bartha et al. 2013; Davies et al. 2019; Moppett et al. 2015). The GDHT protocol used by Bartha and colleagues includes fluid resuscitation prior to anaesthetic induction, intraoperative use of vasoactive support if SAP declined by more than $30 \%$ from pre-anaesthesia values, and optimisation with fluids and dobutamine for stroke volume (SV) and $\mathrm{DO}_{2}$ respectively. Colloid therapy to optimise SV was protocolised by Moppett and co-workers in their IG. Finally, Davies and colleagues applied a GDHT protocol based on SV optimisation by crystalloids and mean arterial pressure maintenance above $30 \%$ of baseline values with vasopressors.

Our IG shows a similar percentage of responders to the first fluid challenge as previously described (Bartha et al. 2013). This lower-than-expected percentage can be explained by the optimisation starting immediately after admission to hospital, according to the ERP applied in both patient cohorts. Total fluid used in our IG is comparable or slightly less than the amounts given in two previous studies' intervention 
groups: 1.078 (Bartha et al. 2013) and $850 \mathrm{ml}$ (Davies et al. 2019) respectively and slightly higher than the volume given in another previous intervention group: $750 \mathrm{ml}$ (Moppett et al. 2015). A lower use of vasopressors in our IG stands out, probably because of following a decision algorithm. The nonapplication of a haemodynamic algorithm may lead to an early use of vasopressors, even if it is not physiologically appropriate for the patient's condition. No IG patients were treated intraoperatively with dobutamine, probably due to the establishment of an individualized $\mathrm{Cl}$ goal and by the absence of intraoperative pathophysiological tributary situations. Fewer patients had been transfused in our IG. In addition to the use of less bleeding surgical techniques (Yu et al. 2015), patients in IG may suffered less haemodilution than patients in CG due to lower amount of fluids received (Ince 2015).

We found a reduction in hospital stay and a significant increased survival in IG patients throughout the first year after surgery. These findings can be explained by the significant reduction in intraoperative complications and postoperative cardiovascular, respiratory and infectious complications, and surgical reinterventions (Monk et al. 2015); (Roche et al. 2005). After adjusting for potential confounding variables, IG membership was a protective factor for one-year mortality.

The results of this study suggest that not only haemodynamic strategy we perform on our patients will influence their outcomes. The type of fluid used during major surgery may affect postoperative results (Heming et al. 2020). The results of the fluid infusion strategy used cannot be evaluated without considering the type of drug used.

Our study has some limitations. It was a single-centre, non-randomised design with a three-years gap between the two study groups. However, no changes were made between groups in the ERP, nor in the composition of the multidisciplinary team or in the care protocols during the study period. IG recruitment rate was lower than expected, probably because of the real emergency surgery status applied to hip fracture patients in this hospital since 2010. Patients with contraindications for haemodynamic monitoring, poor quality signal obtained or with preoperative psychomotor agitation that prevented hemodynamic monitoring were excluded only from the IG. However, our exclusion rate for these reasons $(9 \%)$ is lower than previously reported (Davies et al. 2019), but we cannot rule out that these excluded patients had worse clinical status on arrival in the operating theatre.

Uncontrolled before-and-after study provides less quality evidence than randomised controlled trials (RCT) (Sedgwick 2014). However, this design offers valuable insights into the potential benefits of GDHT protocols under real-life conditions, and can complement evidence from RCT (Saugel et al. 2019). Moreover, this is the largest sample size published to date evaluating the effect of GDHT guided by noninvasive haemodynamic monitoring during hip fracture surgery.

\section{5- Conclusions}

In patients undergoing hip fracture surgery, the use of a GDHT protocol guided by non-invasive hemodynamic monitoring was associated with a reduction in intraoperative complications and 
postoperative cardiovascular, respiratory and infectious, but not postoperative renal complications. This strategy was also associated with shorter hospital stay and higher survival one year after surgery.

\section{6- List Of Abbreviations}

- AKI - Acute Kidney Injury

- CG - Control group

- $\mathrm{Cl}$ - Cardiac Index

- $\mathrm{DO}_{2}$ - Oxygen Delivery

- ERP - Enhanced Recovery Pathway

- FB - Fluid Bolus

- GDHT - Goal-Directed Hemodynamic Therapy

- HR - Hazard Ratio

- IG - Intervention Group

- IQR - Interquartile Range

- MDRD - Modification of Diet in Renal Disease

- METS - Metabolic Equivalents

- PACU - Post-Anaesthetic Care Unit

- PRBC - Packed Red Blood Cells

- SAP - Systolic Arterial Pressure

- $\mathrm{SpO}_{2}$ - Oxygen Saturation

- SV - Stroke Volume

- SVI - Indexed Stroke Volume

- $\mathrm{VO}_{2}$ - Oxygen Consumption

\section{7- Declarations}

7.1. Ethics approval and consent to participate

This manuscript was written according to CONSORT statement. The study was approved by an independent Ethics Committee (Fundació Unio Catalana Hospitals, Chairperson: Dr. Miquel Nolla) on 27 January 2015 (CEIC 15/03). All patients signed an informed consent to participate. The study was conducted according to the Declaration of Helsinki and all local legal and regulatory requirements

\subsection{Consent for publications}

Not applicable 
7.3. Availability of data and materials

The datasets used and/or analysed during this study are available from the corresponding author on reasonable request

\subsection{Competing interest}

Dr Lorente, Dr Jiménez, Dr Ripollés-Melchor and Dr Monge have received conference fees from Edwards Lifesciences.

Dr Lorente \& Dr Ripollés-Melchor have received conference fees from Fresenius Kabi and bioMérieux.

Dr Ripollés-Melchor \& Dr Monge have received conference fees from Dextera Medical

Dr Lorente has received conference fees from Vifor Pharma, financial support for research obtained through Edwards Lifesciences Grant Portal. Economic research support from bioMérieux.

Dr Ripollés-Melchor has received conference fees from MSD

The rest of the authors declare no conflict of interest.

\subsection{Funding}

This research did not receive any specific grant from funding agencies in the public, commercial, or notfor-profit sectors

\subsection{Authors' contributions}

- JVL: Study design, patient recruitment, acquisition of data, review of perioperative complications in IG, analysis and interpretation of data, writing up of the paper and final approval of the version to be published.

- FR: Study design, patient recruitment, acquisition of data, review of perioperative complications in $C G$, analysis and interpretation of data and review of the paper's content.

- AA: Study design, analysis and interpretation of data and review of the paper's content.

- MB: patient recruitment, acquisition of data and review of the paper's content.

- JCP: patient recruitment, acquisition of data and review of the paper's content paper.

- JT: patient recruitment, acquisition of data and review of the paper's content.

- LC: patient recruitment, acquisition of data and review of the paper's content.

- PS: patient recruitment, acquisition of data and review of the paper's content.

- IP: patient recruitment, acquisition of data and review of the paper's content.

- CF: patient recruitment, acquisition of data and review of the paper's content.

- IJL: analysis and interpretation of data and review of the paper's content. 
- JRM: analysis and interpretation of data and review of the paper's content.

- MIMG: analysis and interpretation of data and review of the paper's content.

- JB: Study design, analysis and interpretation of data and review of the paper's content.

All authors have approved the latest version of the manuscript and agree to be responsible for all aspects of the work ensuring that issues relating to the accuracy or completeness of any part of the work have been properly investigated and resolved.

\subsection{Acknowledgements}

We would like to acknowledge the contribution of Dr Omar El Boutrouki and Ms Mercé Castejón for their help in the development of the study.

\section{References}

1. Alecu C, Cuignet-Royer E, Mertes PM, Salvi P, Vespignani H, Lambert M, et al. Pre-existing arterial stiffness can predict hypotension during induction of anaesthesia in the elderly. Br. J. Anaesth. [Internet]. British Journal of Anaesthesia. Published by Elsevier Ltd.; 2010;105(5):583-8. Available from: http://dx.doi.org/10.1093/bja/aeq231

2. Bartha E, Arfwedson C, Imnell A, Fernlund ME, Andersson LE, Kalman S. Randomized controlled trial of goal-directed haemodynamic treatment in patients with proximal femoral fracture. Br. J. Anaesth. 2013;110(4):545-53.

3. Beecham G, Cusack R, Sebastian Vencken. Hypotension during hip fracture surgery and postoperative morbidity. Ir. J. Med. Sci. Irish Journal of Medical Science; 2020;189(3):1087-96.

4. Brienza N, Biancofiore G, Cavaliere F, Corcione A, de Gasperi A, de Rosa RC, et al. Clinical guidelines for perioperative hemodynamic management of non cardiac surgical adult patients. Minerva Anestesiol. 2019;85(12):1315-33.

5. Cecconi M, Parsons AK, Rhodes A. What is a fluid challenge? Curr. Opin. Crit. Care. 2011;17(3):2905.

6. Chowdhury AH, Cox EF, Francis ST, Lobo DN. A randomized, controlled, double-blind crossover study on the effects of 2-L infusions of $0.9 \%$ saline and plasma-lyte ${ }^{\circledR} 148$ on renal blood flow velocity and renal cortical tissue perfusion in healthy volunteers. Ann. Surg. 2012;256(1):18-24.

7. Cowan R, Lim JH, Ong T, Kumar A, Sahota O. The Challenges of Anaesthesia and Pain Relief in Hip Fracture Care. Drugs and Aging. Springer International Publishing; 2017;34(1):1-11.

8. Davies SJ, Yates DR, Wilson RJT, Murphy Z, Gibson A, Allgar V, et al. A randomised trial of noninvasive cardiac output monitoring to guide haemodynamic optimisation in high risk patients undergoing urgent surgical repair of proximal femoral fractures (ClearNOF trial NCT02382185). Perioper. Med. Perioperative Medicine; 2019;9(30):1-11. 
9. Giglio M, Manca F, Dalfino L, Brienza N. Perioperative hemodynamic goal-directed therapy and mortality: A systematic review and meta-analysis with meta-regression. Minerva Anestesiol. 2016;82(11):1199-213.

10. Griffiths R, Babu S, Dixon P, Freeman N, Hurford D, Kelleher E, et al. Guideline for the management of hip fractures 2020: Guideline by the Association of Anaesthetists. Anaesthesia. 2021;76(2):225-37.

11. Grocott MPW, Dushianthan A, Hamilton MA, Mythen MG, Harrison D, Rowan K. Perioperative increase in global blood flow to explicit defined goals and outcomes after surgery: A cochrane systematic review. Br. J. Anaesth. The Author(s); 2013;111(4):535-48.

12. Guinot PG, Bernard E, Defrancq F, Petiot S, Majoub Y, Dupont H, et al. Mini-fluid challenge predicts fluid responsiveness during spontaneous breathing under spinal anaesthesia: An observational study. Eur. J. Anaesthesiol. 2015;32(9):645-9.

13. Hahn RG. Renal injury during hip fracture surgery: an exploratory study. Anestezjol. Intens. Ter. 2015;47(4):284-90.

14. Heming N, Moine P, Coscas R, Annane D. Perioperative fluid management for major elective surgery. Br. J. Surg. 2020;107(2):e56-62.

15. Ince $\mathrm{C}$. Hemodynamic coherence and the rationale for monitoring the microcirculation. Crit. Care [Internet]. BioMed Central Ltd; 2015;19(Suppl 3):S8. Available from:

http://www.ccforum.com/content/19/S3/S8

16. Ishihara H. Kidney function after the intraoperative use of $6 \%$ tetrastarches (HES 130/0.4 and 0.42). J. Anesth. 2014;28(2):249-56.

17. Jacob M, Chappell D, Hofmann-Kiefer K, Conzen P, Peter K, Rehm M. Determinants of insensible fluid loss. Perspiration, protein shift and endothelial glycocalyx. Anaesthesist. 2007;56(8):747-64.

18. Ljungqvist O, Scott M, Fearon KC. Enhanced recovery after surgery a review. JAMA Surg. 2017;152(3):292-8.

19. Lugo G, Arizpe D, Dominguez G RM et al. Relationship between oxygen consumption and oxigen delivery during anesthesia in high-risk surgical patients. Crit. Care Med. 1993;21(1):64-9.

20. Mallat J, Meddour M, Durville E, Lemyze M, Pepy F, Temime J, et al. Decrease in pulse pressure and stroke volume variations after mini-fluid challenge accurately predicts fluid responsiveness. Br. J. Anaesth. 2015;115(3):449-56.

21. Marik PE. Fluid therapy in 2015 and beyond: The mini-fluid challenge and mini-fluid bolus approach. Br. J. Anaesth. 2015;115(3):347-9.

22. Meersch M, Schmidt C, Zarbock A. Perioperative Acute Kidney Injury: An Under-Recognized Problem. Anesth. Analg. 2017;125(4):1223-32.

23. Merry AF, Mitchell SJ. Complications of anaesthesia. Anaesthesia. 2018;73:7-11.

24. Miller TE, Roche AM, Mythen M. Fluid management and goal-directed therapy as an adjunct to Enhanced Recovery After Surgery (ERAS). Can. J. Anesth. 2015;62(2):158-68. 
25. Monk TG, Bronsert MR, Henderson WG, Mangione MP, Sum-Ping STJ, Bentt DR, et al. Association between Intraoperative Hypotension and Hypertension and 30-day Postoperative Mortality in Noncardiac Surgery. Anesthesiology [Internet]. 2015 Aug;123(2):307-19. Available from: http://insights.ovid.com/crossref?an=00000542-201508000-00016

26. Montenij L, Waal E De, Frank M, Beest P Van, Wit A De, Kruitwagen C, et al. Influence of early goaldirected therapy using arterial waveform analysis on major complications after high-risk abdominal surgery: study protocol for a multicenter randomized controlled superiority trial. 2014;1-12.

27. Moppett IK, Rowlands M, Mannings A, Moran CG, Wiles MD, Van DeWalt G, et al. LiDCO-based fluid management in patients undergoing hip fracture surgery under spinal anaesthesia: A randomized trial and systematic review. Br. J. Anaesth. 2015;114(3):444-59.

28. Muller L, Toumi M, Bousquet PJ, Riu-Poulenc B, Louart G, Candela D, et al. An increase in aortic blood flow after an infusion of $100 \mathrm{ml}$ colloid over 1 minute can predict fluid responsiveness: The mini-fluid challenge study. Anesthesiology. 2011;115(3):541-7.

29. Muñoz JL, Gabaldón T, Miranda E, Berrio DL, Ruiz-tovar J, Ronda JM, et al. Goal-Directed Fluid Therapy on Laparoscopic Sleeve Gastrectomy in Morbidly Obese Patients. Obes Surg. 2016;26(11):2648-53.

30. Reguant F, Arnau A, Lorente J V, Maestro L, Bosch J. Efficacy of a multidisciplinary approach on postoperative morbidity and mortality of elderly patients with hip fracture. J. Clin. Anesth. [Internet]. Elsevier; 2019;53(September 2018):11-9. Available from: https://doi.org/10.1016/j.jclinane.2018.09.029

31. Roche JJW, Wenn RT, Sahota O, Moran CG. Effect of comorbidities and postoperative complications on mortality after hip fracture in elderly people: Prospective observational cohort study. Br. Med. J. 2005;331(7529):1374-6.

32. Rocos B, Whitehouse MR, Kelly MB. Resuscitation in hip fractures: a systematic review. Br. Med. J. 2017;7(e015906):1-6.

33. Saugel B, Cecconi M, Wagner JY, Reuter DA. Noninvasive continuous cardiac output monitoring in perioperative and intensive care medicine. Br. J. Anaesth. [Internet]. The Author(s); 2015;114(4):56275. Available from: http://dx.doi.org/10.1093/bja/aeu447

34. Saugel B, Joosten A, Scheeren TWL. Perioperative goal-directed therapy: what's the best study design to investigate its impact on patient outcome? J. Clin. Monit. Comput. [Internet]. Springer Netherlands; 2019;33(3):361-3. Available from: http://dx.doi.org/10.1007/s10877-018-0196-2

35. Sedgwick P. Before and after study designs. BMJ. 2014;349(January):g5074.

36. Tassoudis V, Vretzakis G, Petsiti A, Stamatiou G, Bouzia K, Melekos M, et al. Impact of intraoperative hypotension on hospital stay in major abdominal surgery. J. Anesth. 2011;25(4):492-9.

37. Teboul JL, Saugel B, Cecconi M, De Backer D, Hofer CK, Monnet X, et al. Less invasive hemodynamic monitoring in critically ill patients. Intensive Care Med. Springer Berlin Heidelberg; 2016;42(9):13509. 
38. Veronese N, Maggi S. Epidemiology and social costs of hip fracture. Injury [Internet]. Elsevier Ltd; 2018;49(8):1458-60. Available from: https://doi.org/10.1016/j.injury.2018.04.015

39. Wesseling, K H; de Wit, B; Van der Hoeven, A;Van Goudoever JSJ. Physiocal, calibrating finger vascular physiology for FInapres. Homeostasis. 1995;36(2-3):67-82.

40. Yu J, Zhang C, Li L, Kwong JSW, Xue L, Zeng X, et al. Internal fixation treatments for intertrochanteric fracture: A systematic review and meta-Analysis of randomized evidence. Sci. Rep. [Internet]. Nature Publishing Group; 2015;5(June):1-11. Available from: http://dx.doi.org/10.1038/srep18195

\section{Tables}


Table 1

Baseline characteristics according to group allocation

\begin{tabular}{|c|c|c|}
\hline & $\begin{array}{l}\text { Control (CG) } \\
n=272\end{array}$ & $\begin{array}{l}\text { Intervention (IG) } \\
n=279\end{array}$ \\
\hline Age & $84.9 \pm 6.2$ & $85.2 \pm 7.4$ \\
\hline 65 to $<75$ years & $15(5.5 \%)$ & $30(10.8 \%)$ \\
\hline 75 to $<85$ years & $125(46.0 \%)$ & $97(34.8 \%)$ \\
\hline$\geq 85$ years & $132(48.5 \%)$ & $152(54.5 \%)$ \\
\hline \multicolumn{3}{|l|}{ Gender } \\
\hline Male & $84(30.9 \%)$ & $68(24.4 \%)$ \\
\hline Female & $188(69.1 \%)$ & $211(75.6 \%)$ \\
\hline \multicolumn{3}{|l|}{ ASA } \\
\hline I- II & $85(31.2 \%)$ & $41(14.7 \%)$ \\
\hline III - IV & $187(68.8 \%)$ & $238(85.3 \%)$ \\
\hline \multicolumn{3}{|l|}{ Charlson comorbidity index } \\
\hline Absence de comorbidity $(0-1)$ & $125(46.0 \%)$ & $109(39.1 \%)$ \\
\hline Low comorbidity (2) & $50(18.4 \%)$ & $57(20.4 \%)$ \\
\hline High comorbidity (3 or more) & $97(35.7 \%)$ & $113(40.5 \%)$ \\
\hline \multicolumn{3}{|l|}{ Cardiovascular history } \\
\hline Valvulopathy & $21(7.7 \%)$ & $31(11.1 \%)$ \\
\hline Arrhythmia & $73(26.8 \%)$ & $58(20.8 \%)$ \\
\hline Ischemic cardiopathy & $17(6.3 \%)$ & $29(10.4 \%)$ \\
\hline Pulmonary thromboembolism (PTE) & $1(0.4 \%)$ & $3(1.1 \%)$ \\
\hline Hypertension & $177(65.1 \%)$ & $212(76.0 \%)$ \\
\hline Total number of drugs & 6 (IQR 4 to 8) & 7 (IQR 5 to 10$)$ \\
\hline$\leq 4$ drugs & $89(32.7 \%)$ & $68(24.4 \%)$ \\
\hline$>4$ drugs & $183(67.3 \%)$ & $211(75.6 \%)$ \\
\hline \multicolumn{3}{|l|}{ Type of fracture } \\
\hline Intra-capsular & $121(44.5 \%)$ & $124(44.4 \%)$ \\
\hline
\end{tabular}




\begin{tabular}{|c|c|c|}
\hline & $\begin{array}{l}\text { Control (CG) } \\
n=272\end{array}$ & $\begin{array}{l}\text { Intervention (IG) } \\
\mathrm{n}=\mathbf{2 7 9}\end{array}$ \\
\hline Extra-capsular & $151(55.5 \%)$ & $155(55.6 \%)$ \\
\hline \multicolumn{3}{|l|}{ Hemoglobin at admission } \\
\hline Hemoglobin $>12 \mathrm{~g} / \mathrm{dl}$ & $159(58.5 \%)$ & $169(60.6 \%)$ \\
\hline Hemoglobin $\leq 12 \mathrm{~g} / \mathrm{dl}$ & $113(41.5 \%)$ & $110(39.4 \%)$ \\
\hline \multicolumn{3}{|l|}{ Creatinine at admission } \\
\hline Creatinine $\leq 1.09 \mathrm{mg} / \mathrm{dl}$ & $178(65.7 \%)$ & $175(62.7 \%)$ \\
\hline Creatinine $>1.09 \mathrm{mg} / \mathrm{dl}$ & $93(34.3 \%)$ & $104(37.3 \%)$ \\
\hline \multicolumn{3}{|l|}{ Anesthesia } \\
\hline General & $28(10.3 \%)$ & $28(10.0 \%)$ \\
\hline Spinal & $244(89.7 \%)$ & $251(90.0 \%)$ \\
\hline \multicolumn{3}{|l|}{ Type of implant } \\
\hline Hip prosthesis & $103(37.9 \%)$ & $102(36.6 \%)$ \\
\hline Dynamic hip screw & $122(44.9 \%)$ & $57(20.4 \%)$ \\
\hline Intramedullary nail & $43(15.8 \%)$ & $118(42.3 \%)$ \\
\hline Others & $4(1.5 \%)$ & $2(0.7 \%)$ \\
\hline \multicolumn{3}{|l|}{ Surgical delay } \\
\hline$\leq 48$ hours & $150(55.1)$ & $191(68.5)$ \\
\hline$>48$ hours & $122(44.9)$ & $88(31.5)$ \\
\hline Surgery time (minutes) & 80 (IQR 65 to 105$)$ & 90 (IQR 70 to 120$)$ \\
\hline
\end{tabular}

Mean \pm Standard deviation; $\mathrm{n}(\%)$; median (IQR $25^{\text {th }}$ percentile to $75^{\text {th }}$ percentile). 
Table 2

Main and secondary outcomes at one-year follow-up.

\begin{tabular}{|c|c|c|c|}
\hline & $\begin{array}{l}\text { Control (CG) } \\
n=272\end{array}$ & $\begin{array}{l}\text { Intervention (IG) } \\
\mathrm{n}=\mathbf{2 7 9}\end{array}$ & $\begin{array}{l}\mathrm{p}- \\
\text { value }\end{array}$ \\
\hline \multicolumn{4}{|l|}{ Intraoperative complications } \\
\hline Hemodynamic instability & $102(37.5 \%)$ & $78(28.0 \%)$ & $0.017^{\mathrm{a}}$ \\
\hline$N^{0}$ episodes hemodynamic instability ${ }^{1}$ & 2 (IQR 1 to 4$)$ & 1 (IQR 1 to 2 ) & $<.001^{b}$ \\
\hline Arrhythmias & $6(2.2 \%)$ & $2(0.7 \%)$ & $0.172^{c}$ \\
\hline Postoperative complications & $123(45.2 \%)$ & $118(42.3 \%)$ & $0.489^{a}$ \\
\hline Cardiovascular & $51(18.8 \%)$ & $20(7.2 \%)$ & $<.001^{\mathrm{a}}$ \\
\hline Major & $12(4.4 \%)$ & $11(3.9 \%)$ & $0.783^{a}$ \\
\hline Myocardial infarction & $1(0.4 \%)$ & $0(0.0 \%)$ & $0.494^{c}$ \\
\hline Cardiorespiratory arrest & $3(1.1 \%)$ & $6(2.2 \%)$ & $0.505^{c}$ \\
\hline Acute pulmonary edema & $8(2.9 \%)$ & $5(1.8 \%)$ & $0.374^{\mathrm{a}}$ \\
\hline Pulmonary Thromboembolism & $0(0.0 \%)$ & $0(0.0 \%)$ & - \\
\hline Cardiorespiratory arrest & $0(0.0 \%)$ & $0(0.0 \%)$ & - \\
\hline Minor & $40(14.7 \%)$ & $12(4.3 \%)$ & $<.001^{\mathrm{a}}$ \\
\hline Hemodynamic instability & $34(12.5 \%)$ & $5(1.8 \%)$ & $<0.001^{\mathrm{a}}$ \\
\hline Arrhythmias & $4(1.5 \%)$ & $7(2.5 \%)$ & $0.384^{\mathrm{a}}$ \\
\hline Others & $2(0.7 \%)$ & $1(0.4 \%)$ & $0.620^{c}$ \\
\hline Respiratory & $41(15.1 \%)$ & $10(3.6 \%)$ & $<.001^{\mathrm{a}}$ \\
\hline Hypoxia & $17(6.3 \%)$ & $2(0.7 \%)$ & $0.001^{\mathrm{a}}$ \\
\hline $\begin{array}{l}\text { Decompensation of Chronic Obstructive } \\
\text { Pulmonary Disease }\end{array}$ & $6(2.2 \%)$ & $1(0.4 \%)$ & $0.066^{c}$ \\
\hline Acute respiratory infection & $16(5.9 \%)$ & $5(1.8 \%)$ & $0.012^{a}$ \\
\hline
\end{tabular}




\begin{tabular}{|c|c|c|c|}
\hline & $\begin{array}{l}\text { Control (CG) } \\
n=272\end{array}$ & $\begin{array}{l}\text { Intervention (IG) } \\
\mathrm{n}=\mathbf{2 7 9}\end{array}$ & $\begin{array}{l}\mathrm{p} \text { - } \\
\text { value }\end{array}$ \\
\hline Others & $3(1.1 \%)$ & $2(0.7 \%)$ & $0.682^{c}$ \\
\hline Renal & $33(12.1 \%)$ & $94(33.7 \%)$ & $\begin{array}{l}< \\
0.001^{\mathrm{a}}\end{array}$ \\
\hline Infections & $57(21.0 \%)$ & $11(3.9 \%)$ & $\begin{array}{l}< \\
0.001^{\mathrm{a}}\end{array}$ \\
\hline Surgical wound & $8(2.9 \%)$ & $0(0.0 \%)$ & $0.003^{c}$ \\
\hline Urinary & $47(17.3 \%)$ & $10(3.6 \%)$ & $\begin{array}{l}< \\
0.001^{\mathrm{a}}\end{array}$ \\
\hline Systemic & $3(1.1 \%)$ & $2(0.7 \%)$ & $0.682^{\mathrm{a}}$ \\
\hline \multicolumn{4}{|l|}{ Secondary to spinal anesthesia } \\
\hline Hematoma/infection/neurological lesion & $0(0.0 \%)$ & $0(0.0 \%)$ & - \\
\hline Surgical re-intervention & $6(2.2 \%)$ & $0(0.0 \%)$ & $0.014^{c}$ \\
\hline Length of stay (days) & 11 (IQR 8 to 16 ) & 8 (IQR 6 to 11$)$ & $\begin{array}{l}< \\
0.001^{b}\end{array}$ \\
\hline Destination after discharge & & & $0.327^{\mathrm{a}}$ \\
\hline Convalescence & $128(49.8 \%)$ & $142(52.0 \%)$ & \\
\hline Family home & $81(31.5 \%)$ & $71(26.0 \%)$ & \\
\hline Residence & $48(18.7 \%)$ & $60(22.0 \%)$ & \\
\hline Thirty-day readmission & $29(11.3 \%)$ & $21(7.7 \%)$ & $0.157^{a}$ \\
\hline Survival & & & $0.003^{d}$ \\
\hline 1-month & $\begin{array}{l}91.2 \%(87.1- \\
94.0 \%)\end{array}$ & $\begin{array}{l}96.8 \% \text { (93.9 to } \\
98.3 \%)\end{array}$ & \\
\hline 3-month & $\begin{array}{l}88.6 \%(84.2- \\
91.8 \%)\end{array}$ & $\begin{array}{l}95.3 \% \text { (92.1 to } \\
97.3 \%)\end{array}$ & \\
\hline 6-month & $\begin{array}{l}83.0 \%(78.0- \\
87.0 \%)\end{array}$ & $\begin{array}{l}90.2 \% \text { (86.0 to } \\
93.2 \%)\end{array}$ & \\
\hline 12-month & $\begin{array}{l}73.4 \%(67.7- \\
78.3 \%)\end{array}$ & $\begin{array}{l}83.8 \% \text { (78.8 to } \\
87.7 \%)\end{array}$ & \\
\hline
\end{tabular}

Mean \pm Standard deviation; $\mathrm{n}(\%)$; median (range $\mathrm{x}$ to $\mathrm{y}$ ) or median (IQR $25^{\text {th }}$ percentile to $75^{\text {th }}$ percentile). 
a Pearson X2. b Mann-Whitney U; ${ }^{c}$ Fisher's exact test; ${ }^{d}$ Log-rank test.

${ }^{1}$ In patients with hemodynamic instability 
Table 3

Total fluid volumes, vasopressor doses and perioperative blood transfusion

\begin{tabular}{|c|c|c|c|c|c|}
\hline & \multicolumn{2}{|c|}{$\begin{array}{l}\text { Control (CG) } \\
n=272\end{array}$} & \multicolumn{2}{|c|}{$\begin{array}{l}\text { Intervention (IG) } \\
\mathrm{n}=\mathbf{2 7 9}\end{array}$} & \multirow[t]{2}{*}{$\begin{array}{l}\mathrm{p} \text { - } \\
\text { value }\end{array}$} \\
\hline & $\mathrm{n}(\%)$ & median (IQR) & $\mathrm{n}(\%)$ & median (IQR) & \\
\hline \multicolumn{6}{|l|}{ Fluid volumes } \\
\hline Total fluids (ml) & $\begin{array}{l}272 \\
(100 \%)\end{array}$ & $\begin{array}{l}2600 \text { (IQR } 1700 \\
\text { to } 2700)\end{array}$ & $\begin{array}{l}279 \\
(100 \%)\end{array}$ & $\begin{array}{l}850 \text { (IQR } 750 \text { to } \\
1050)\end{array}$ & 0.001 \\
\hline $\begin{array}{l}\text { Fluid creep -antibiotic } \\
\text { prophylaxis- }(\mathrm{ml})\end{array}$ & $\begin{array}{l}272 \\
(100 \%)\end{array}$ & $\begin{array}{l}200 \text { (IQR } 200 \text { to } \\
200)\end{array}$ & $\begin{array}{l}279 \\
(100 \%)\end{array}$ & $\begin{array}{l}200 \text { (IQR } 100 \text { to } \\
200)\end{array}$ & 0.001 \\
\hline Intraoperative fluids (ml) & $\begin{array}{l}272 \\
(100 \%)\end{array}$ & $\begin{array}{l}2500 \text { (IQR } 2000 \\
\text { to } 2500)\end{array}$ & $\begin{array}{l}279 \\
(100 \%)\end{array}$ & $\begin{array}{l}700 \text { (IQR } 550 \text { to } \\
900)\end{array}$ & 0.001 \\
\hline Crystalloids (ml) & $\begin{array}{l}253 \\
(94.5 \%)\end{array}$ & $\begin{array}{l}2000(\text { IQR } 2000 \\
\text { to } 2000)\end{array}$ & $\begin{array}{l}278 \\
(99.6 \%)\end{array}$ & $\begin{array}{l}650 \text { (IQR } 550 \text { to } \\
850)\end{array}$ & 0.001 \\
\hline Saline $(\mathrm{ml})$ & $\begin{array}{l}68 \\
(25.0 \%)\end{array}$ & $\begin{array}{l}1000(\text { IQR } 1000 \\
\text { to } 1000)\end{array}$ & $\begin{array}{l}267 \\
(95.7 \%)\end{array}$ & $\begin{array}{l}650 \text { (IQR } 550 \text { to } \\
850 \text { ) }\end{array}$ & 0.001 \\
\hline Lactated Ringer (ml) & $\begin{array}{l}201 \\
(73.9 \%)\end{array}$ & $\begin{array}{l}1000(\text { IQR } 1000 \\
\text { to } 1000)\end{array}$ & $\begin{array}{l}12 \\
(4.3 \%)\end{array}$ & $\begin{array}{l}1050 \text { (IQR } 850 \\
\text { to } 1237)\end{array}$ & 0.889 \\
\hline Isofundin ${ }^{\circledR}(\mathrm{ml})$ & $\begin{array}{l}22 \\
(8.1 \%)\end{array}$ & $\begin{array}{l}500 \text { (IQR } 500 \text { to } \\
500)\end{array}$ & - & - & - \\
\hline Colloids (ml) & $\begin{array}{l}161 \\
(59.2 \%)\end{array}$ & $\begin{array}{l}500 \text { (IQR } 500 \text { to } \\
500)\end{array}$ & $\begin{array}{l}25 \\
(9.0 \%)\end{array}$ & $\begin{array}{l}300 \text { (IQR } 200 \text { to } \\
500)\end{array}$ & 0.001 \\
\hline Voluven $®(\mathrm{ml})$ & $\begin{array}{l}153 \\
(56.3 \%)\end{array}$ & $\begin{array}{l}500 \text { (IQR } 500 \text { to } \\
500)\end{array}$ & $\begin{array}{l}25 \\
(9.0 \%)\end{array}$ & $\begin{array}{l}300(\text { IQR } 200 \text { to } \\
500)\end{array}$ & 0.001 \\
\hline Gelaspan® $(\mathrm{ml})$ & $\begin{array}{l}11 \\
(4.0 \%)\end{array}$ & $\begin{array}{l}500(\text { IQR } 500 \\
\text { to500) }\end{array}$ & - & - & - \\
\hline Vasopressor & $\begin{array}{l}108 \\
(39.7 \%)\end{array}$ & & $\begin{array}{l}71 \\
(25.5 \%)\end{array}$ & & $\begin{array}{l}< \\
0.001\end{array}$ \\
\hline Ephedrine (mg) & $\begin{array}{l}108 \\
(39.7 \%)\end{array}$ & 15 (IQR 10 to 30) & $\begin{array}{l}65 \\
(23.3 \%)\end{array}$ & $\begin{array}{l}10 \text { (IQR } 10 \text { to } \\
20)\end{array}$ & 0.002 \\
\hline Phenylephrine (mg) & - & - & $\begin{array}{l}11 \\
(4.0 \%)\end{array}$ & $\begin{array}{l}100 \text { (IQR } 50 \text { to } \\
150)\end{array}$ & - \\
\hline Noradrenaline (mg) & $2(0.7 \%)$ & 3.5 (IQR 2 to 3.5$)$ & - & - & - \\
\hline Blood transfusion & $\begin{array}{l}200 \\
(73.5 \%)\end{array}$ & - & $\begin{array}{l}124 \\
(44.4 \%)\end{array}$ & - & $\dot{0.001}$ \\
\hline Number of PRBC ${ }^{1}$ & & 2 (IQR 2 to 4$)$ & & 2 (IQR 1 to 2) & $\begin{array}{l}< \\
0.001\end{array}$ \\
\hline
\end{tabular}




\begin{tabular}{|c|c|c|c|}
\hline & $\begin{array}{l}\text { Control (CG) } \\
n=272\end{array}$ & $\begin{array}{l}\text { Intervention (IG) } \\
n=279\end{array}$ & $\begin{array}{l}\mathrm{p} \text { - } \\
\text { value }\end{array}$ \\
\hline Fluid Challenge Responder & - & $\begin{array}{l}82 \\
(29.4 \%)\end{array}$ & - \\
\hline
\end{tabular}

Median (IQR $25^{\text {th }}$ percentile to $75^{\text {th }}$ percentile). PRBC: Packed Red Blood Cells. ${ }^{1}$ About transfused patients.

Figures 

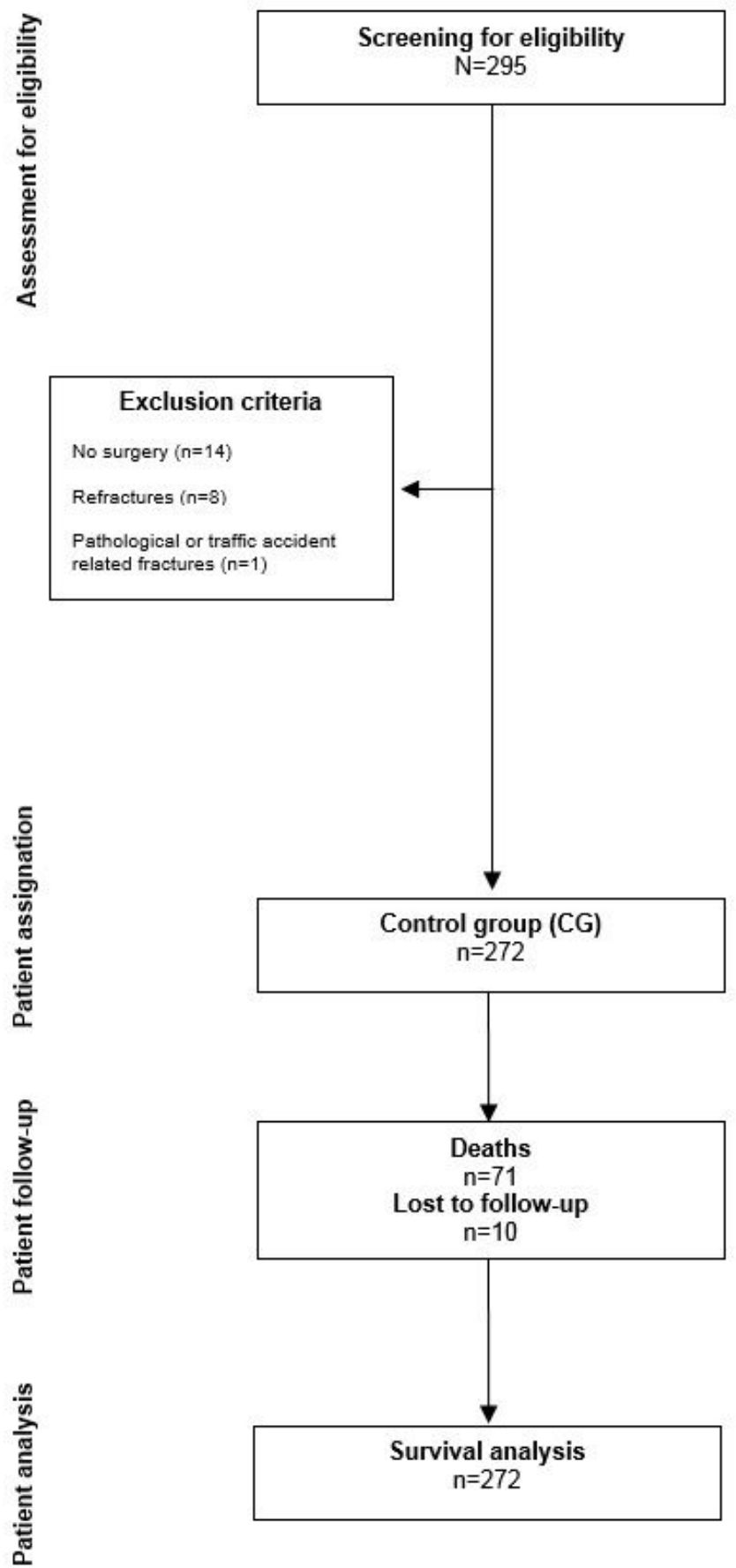

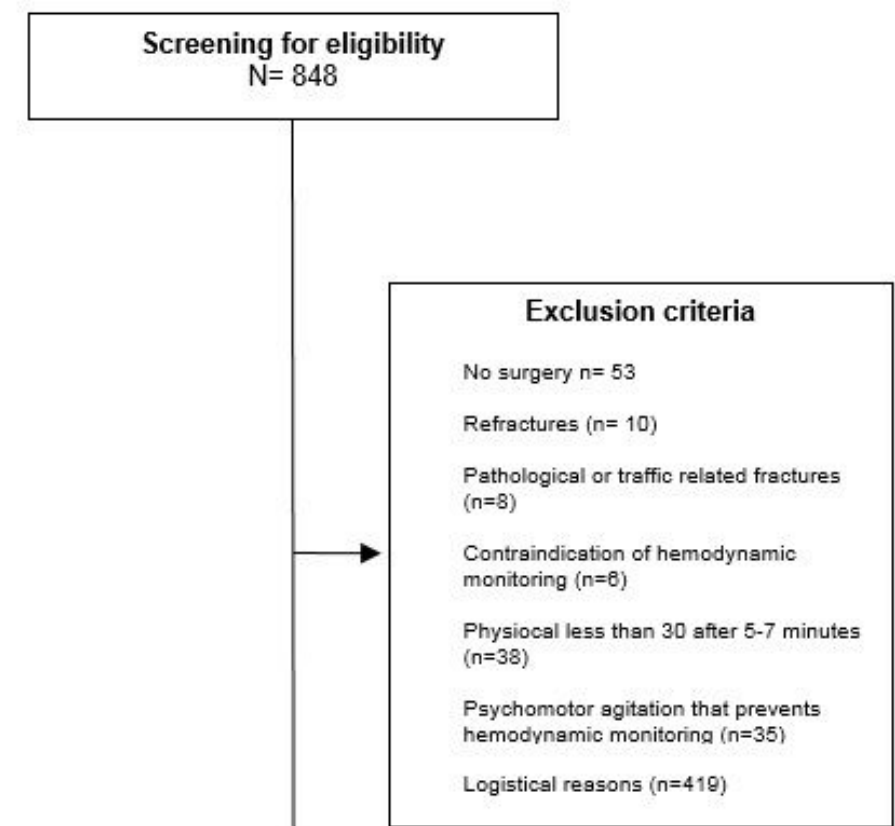

\section{Figure 1}

Flow chart of patients during recruitment and 12-month follow-up. 
Phase 1: Preoperative resuscitation

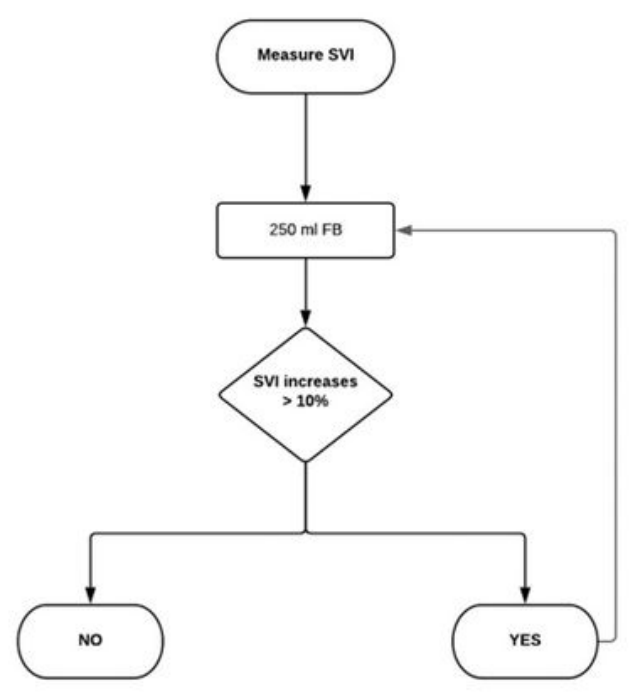

Phase 2: Post-induction optimization

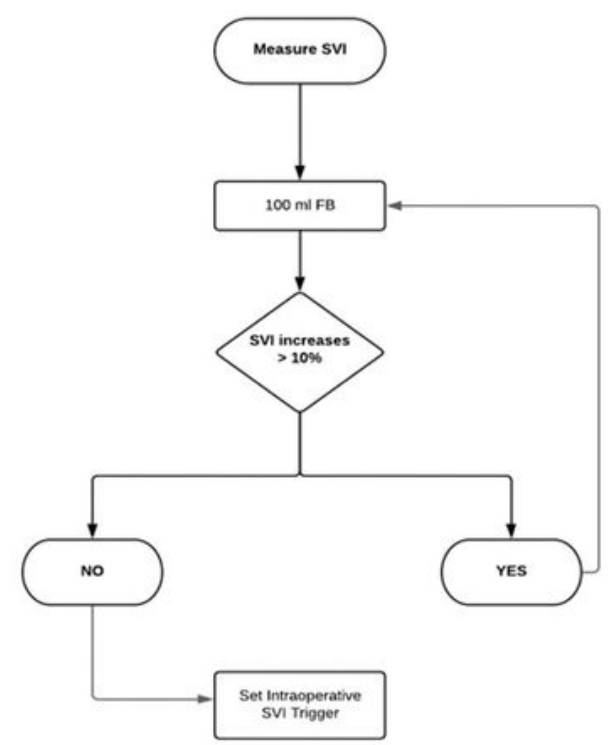

Phase 3: Maintenance during surgery

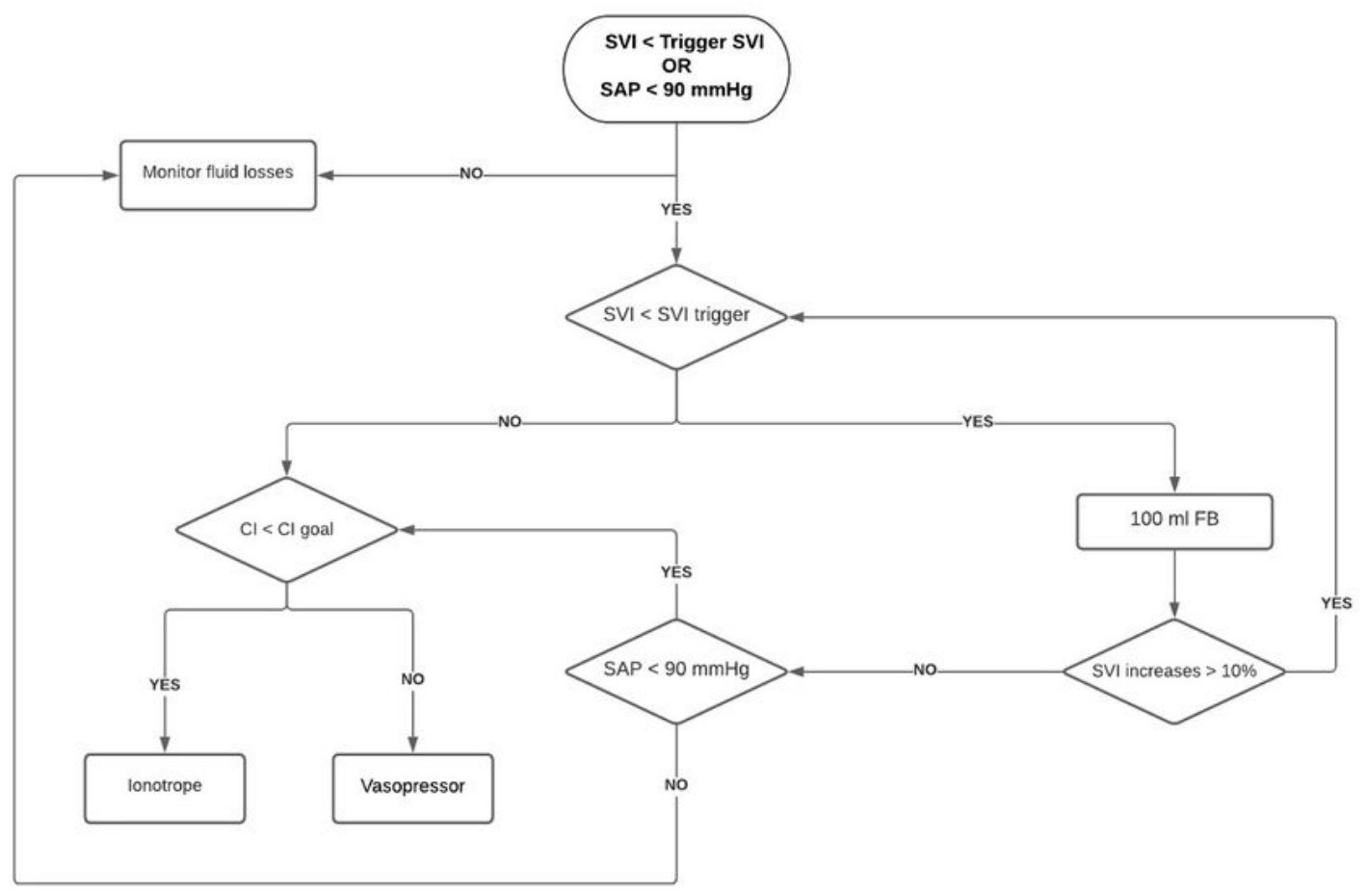

Figure 2

Algorithms for goal-directed haemodynamic therapy phases. 


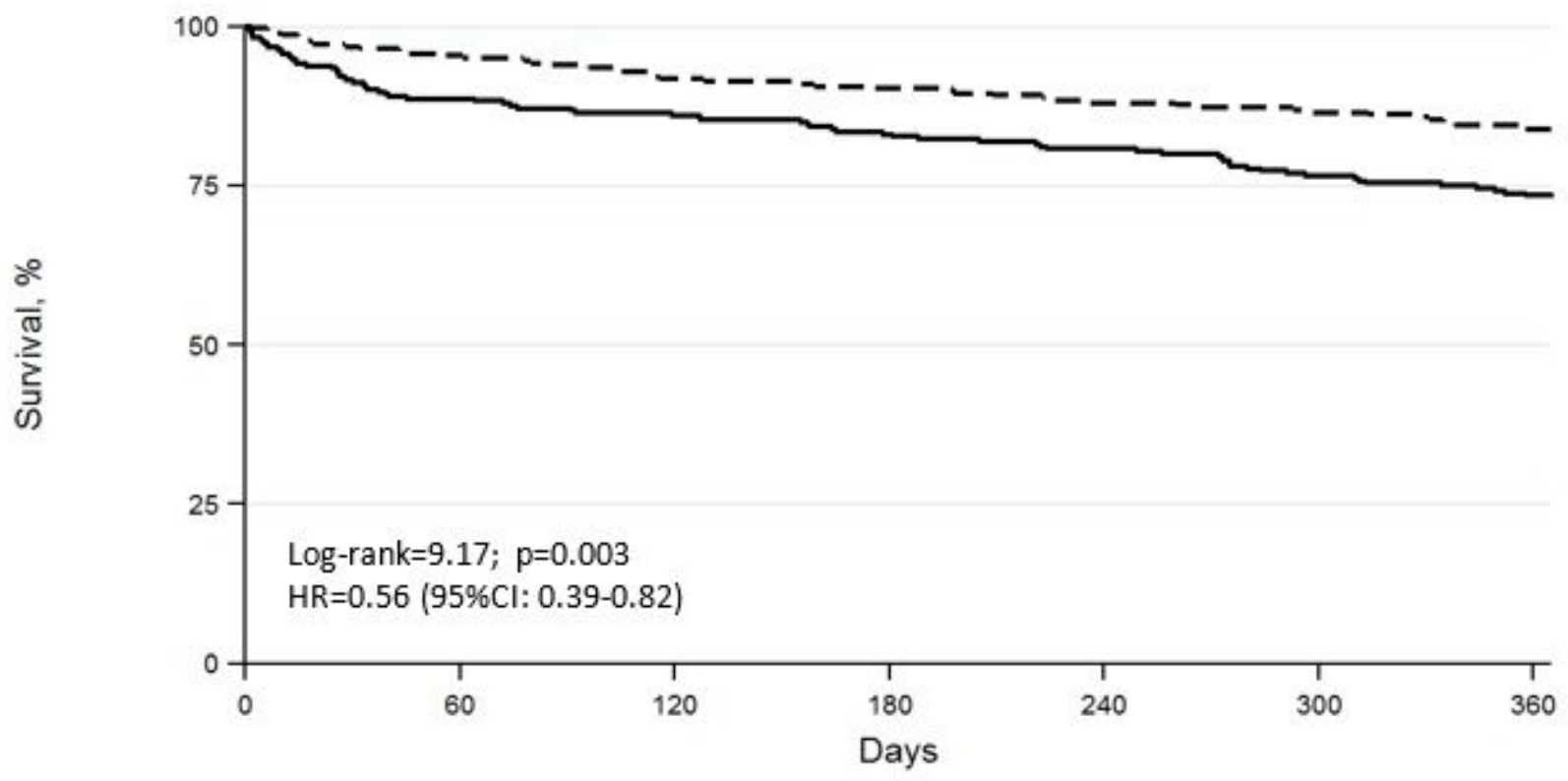

No. at risk

$\begin{array}{cccccccc}\text { CG } & 272 & 240 & 230 & 221 & 210 & 199 & 191 \\ \text { IG } & 279 & 263 & 251 & 244 & 236 & 229 & 217 \\ & & & & & \end{array}$

\section{Figure 3}

Kaplan-Meier survival curves according to group allocation. Crude hazard ratio for one-year survival

\section{Supplementary Files}

This is a list of supplementary files associated with this preprint. Click to download.

- AdditionalFiles.docx 